\title{
Increasing Selenium Concentration in Milk: Effects of Amount of Selenium from Yeast and Cereal Grain Supplements
}

\author{
J. W. Heard, ${ }^{\star}$ C. R. Stockdale, ${ }^{* 1}$ G. P. Walker, ${ }^{\star}$ C. M. Leddin, ${ }^{*}$ F. R. Dunshea,† G. H. Mclntosh, $\neq$ \\ P. M. Shields,§ A. McKenna,\| G. P. Young,‡ and P. T. Doyle* \\ *Primary Industries Research Victoria (PIRVic), Department of Primary Industries, Kyabram Centre, 120 Cooma Road, Kyabram, \\ Victoria 3620, Australia \\ †National Centre of Excellence in Functional Foods, Primary Industries Research Victoria (PIRVic), Department of Primary Industries, \\ Werribee Centre, 600 Sneydes Road, Werribee, Victoria 3030, Australia \\ ¥Department of Medicine, Flinders University of South Australia, Bedford Park, South Australia 5042, Australia \\ §Alltech Biotechnology Pty. Ltd., 68-70 Nissan Drive, Dandenong South, Victoria 3175, Australia \\ ||Tatura Milk Industries Ltd., PO Box 213, Tatura, Victoria 3616, Australia
}

\begin{abstract}
Two experiments were conducted to establish responses in milk Se concentrations in grazing dairy cows to different amounts of dietary Se yeast, and to determine the effects of the Se concentration of the basal diet. The hypothesis tested was that the response in milk, blood, and tissue Se concentrations to supplemental Se would not be affected by whether the Se was from the basal diet or from Se yeast. In addition, by conducting a similar experiment in either early (spring; experiment 1) or late (autumn; experiment 2) lactation, we hypothesized that different Se input-output relationships would result. Both 6 -wk experiments involved 60 multiparous Holstein-Friesian cows, all of which had calved in spring. They were allocated to 1 of 10 dietary Se treatments that included 2 types of crushed triticale grain (low Se, approximately $165 \mu \mathrm{g}$ of Se/kg of DM; or high Se, approximately $580 \mu \mathrm{g} / \mathrm{kg}$ of DM) fed at $4 \mathrm{~kg}$ of $\mathrm{DM} / \mathrm{d}$, and $1 \mathrm{~kg}$ of $\mathrm{DM} / \mathrm{d}$ of pellets formulated to carry 5 quantities of Se yeast $(0,4,8,12$, or $16 \mathrm{mg}$ of Se). Daily total Se intakes ranged from $<2$ to $>18 \mathrm{mg} / \mathrm{cow}$ in both experiments. Milk Se concentrations plateaued after 15 and $7 \mathrm{~d}$ of supplementation in experiments 1 and 2, respectively, and then remained at plateau concentrations. Average milk Se concentrations for the plateau period increased as the amount of Se yeast increased, and low- and high-Se grain treatments were different at all quantities of Se yeast, although there was a tendency for this difference to diminish at the greatest concentrations of yeast. There were significant positive, linear relationships between Se intake and the concentrations of Se in milk, which were not affected by the source of Se, and the relationships were similar
\end{abstract}

Received November 30, 2006.

Accepted April 23, 2007.

${ }^{1}$ Corresponding author: richard.stockdale@dpi.vic.gov.au for both experiments. Therefore, the output of Se in milk in experiment 1 was greater than that in experiment 2 because the milk yield of the cows in early lactation was greater. The estimated proportions of Se partitioned to destinations other than milk and feces increased with the amount of Se in the diet and were greater in experiment 2 than in experiment 1 , a result that was supported by Se concentrations in whole blood and plasma and in semitendinosus muscle tissue. If high-Se products are to be produced for human nutrition, it is important to be able to develop feeding systems that produce milk with consistent and predictable Se concentrations so that products can consistently meet specifications. The results indicate that this objective is achievable.

Key words: selenium, selenium yeast, dairy cow, pasture-fed

\section{INTRODUCTION}

Recommended dietary allowances of Se for humans are approximately $60 \mu \mathrm{g} / \mathrm{d}$, and tolerable upper intakes are approximately $400 \mu \mathrm{g} / \mathrm{d}$ for adults (Institute of Medicine, 2000). Even at maximum tolerable amounts, much of this could be supplied by dairy products from milk with elevated Se concentrations. Selenium concentrations in cow's milk vary within and between dairy regions in Australia (Tinggi et al., 2001). Average Se concentrations in milk from cows grazing pastures and supplemented with cereal grain-based concentrates are approximately $10 \mu \mathrm{g} / \mathrm{kg}$ in northern Victoria (Heard et al., 2004b; Walker et al., 2004) and 6 to $11 \mu \mathrm{g} / \mathrm{kg}$ in northern Queensland (R. G. Walker, Department of Primary Industries and Fisheries, Kairi, Queensland; personal communication). Binnerts (1979) reported milk Se concentrations of 3 to $5 \mu \mathrm{g}$ of Se/kg of milk from cattle in low-Se areas in the Netherlands and 6 to 11 $\mu \mathrm{g} / \mathrm{kg}$ for those from high-Se areas. Variations in Se 
concentrations in pastures (10 to $>50 \mu \mathrm{g}$ of $\mathrm{Se} / \mathrm{kg}$ of DM; Caple et al., 1980) may lead to variations in concentrations in milk, but the effects are likely to be relatively small unless significant amounts of Se are added in fertilizer (Aro et al., 1998). The Se concentrations in concentrate supplements, such as wheat (1 to $117 \mu \mathrm{g} /$ $\mathrm{kg}$ of DM) and lupins (10 to $488 \mu \mathrm{g} / \mathrm{kg}$ of DM), vary to a greater degree than those in pasture (White et al., 1981) and are therefore more likely to affect concentrations in milk.

Many dairy companies are increasing their interest in developing specialty products. Specifically in relation to Se, the challenge is to develop dairy feeding systems that produce milk with consistent and predictable Se concentrations so that Se-enriched products can consistently meet predetermined specifications. The purpose may be to meet recommended daily intakes for humans (MacRae, 2004), or to provide products for use in preventive health (Heard et al., 2004b). Considerable interest exists in supplementing the diets of cows with organic Se as a means of enhancing concentrations in milk and dairy products. Better responses (increase in Se in milk per unit of Se consumed) have been obtained from feeding Se yeast compared with feeding equivalent quantities of inorganic Se sources such as sodium selenate (Ortman and Pehrson, 1999) or sodium selenite (Ortman and Pehrson, 1997, 1999; Givens et al., 2004). As well as the source of Se, other factors that may influence the output of Se in milk include milk protein concentration or production, stage of lactation, and diet. Most Se in milk is associated with milk proteins. Van Dael et al. (1991, as cited by Givens et al., 2004) reported 55 to $75 \%$ of milk Se in CN, 17 to $38 \%$ in whey, and only $7 \%$ in fat, and milk protein concentration and composition can be affected by both stage of lactation and diet.

Two experiments were conducted to establish responses in milk Se concentration to different amounts of Se yeast, and to determine the effects of the Se concentration in the basal diet. The hypothesis tested was that the responses in milk, blood, and tissue Se concentrations to additional dietary Se would not be affected by whether the Se was supplied by the basal diet or from Se yeast. In addition, by conducting a similar experiment with grazing dairy cows in either early (spring) or late (autumn) lactation, we hypothesized that different Se input-output relationships would result.

\section{MATERIALS AND METHODS}

\section{Experimental Design}

All procedures were conducted with protocols approved by the Northern Victorian Animal Ethics Com- mittee. Two experiments were conducted at the Kyabram Center of the Victorian Department of Primary Industries $\left(36^{\circ} 20^{\prime} \mathrm{S}, 145^{\circ} 04^{\prime} \mathrm{E}\right)$ with spring-calved, multiparous Holstein-Friesian cows. Both experiments involved 60 cows that were allocated to 10 groups of 6 based on milk production [experiment 1, $29.9 \pm 3.13$ (SD) $\mathrm{kg} / \mathrm{d}$; experiment $2,15.8 \pm 1.76 \mathrm{~kg} / \mathrm{d}$ ], milk protein concentration ( $3.25 \pm 0.259 \% ; 3.45 \pm 0.214 \%)$, BCS (4.4 \pm 0.55 units; $4.3 \pm 0.45$ units $)$, and BW (522 $\pm 57.8 \mathrm{~kg}$; $578 \pm 54.3 \mathrm{~kg}$ ). The cows were $43 \pm 11.5$ (spring) and $238 \pm 11.7$ (autumn) DIM at the start of experiments 1 and 2, respectively. Cows on all dietary treatments grazed irrigated perennial pasture, composed principally of perennial ryegrass (Lolium perenne L.) and white clover (Trifolium repens L.), as a single herd at daily allowances of 35 to $40 \mathrm{~kg}$ of DM/cow.

Dietary treatments included 2 types of concentrate supplement, low- or high-Se rolled triticale, fed at $4 \mathrm{~kg}$ of $\mathrm{DM} / \mathrm{d}$, and 5 quantities of Se yeast produced from Saccharomyces cerevisiae CNCM I-3060 (Sel-Plex, Alltech Biotechnology, Nicholasville, KY; 0, 4, 8, 12, and $16 \mathrm{mg}$ of Se/d) carried in $1 \mathrm{~kg}$ of $\mathrm{DM} / \mathrm{d}$ of triticale grain pellets. The pellets were made from the low-Se triticale.

\section{Cow Management and Measurements}

Before treatments commenced in experiment 1 , the cows grazed as one group for $7 \mathrm{~d}$ and received $4 \mathrm{~kg}$ of $\mathrm{DM} / \mathrm{d}$ of low-Se triticale. Body weight and BCS were measured $3 \mathrm{~d}$ before treatments commenced and milk production was measured daily. Milk composition was determined on one occasion. Treatments commenced at the a.m. feeding on October $5(\mathrm{~d} 1)$ and finished after the p.m. feeding on November 15 (d 42). Before treatments commenced in experiment 2 , the cows grazed as one group for $14 \mathrm{~d}$ and received $6 \mathrm{~kg}$ of $\mathrm{DM} / \mathrm{d}$ of low-Se triticale. Body weight and BCS were measured $3 \mathrm{~d}$ before treatments commenced and milk production was measured daily. Milk composition was again determined on one occasion. Treatments commenced at the a.m. feeding on April 19 (d 1) and finished after the p.m. feeding on May 27 (d 39).

Pasture height was measured on 2 to $3 \mathrm{~d}$ each week using a rising plate meter (Earle and McGowan, 1979), and pregrazing pasture mass was then estimated using published equations relating plate meter height to pasture mass (kg of DM/ha; Heard et al., 2004a). The area offered to the cows was calculated to provide a daily pasture allowance of approximately 40 (experiment 1 ) or 35 (experiment 2) $\mathrm{kg}$ of DM/cow. Paddocks were measured and electric fencing erected for the following 2 to $3 \mathrm{~d}$ of grazing. The herd was offered almost half of their daily pasture allowance after the a.m. milking and the remaining pasture after the p.m. milking. The cows 
were given the opportunity to back-graze over the a.m. allocation in the p.m.

Nutritive characteristics of the pasture consumed were estimated by taking representative samples of pasture cut to a simulated grazing height of approximately $4 \mathrm{~cm}$. At least 15 quadrats along a defined transect across the grazing area were cut and bulked for each week. Subsamples of approximately $100 \mathrm{~g}$ of fresh weight were oven-dried at $60^{\circ} \mathrm{C}$ for $72 \mathrm{~h}$, ground to pass through a $0.5-\mathrm{mm}$ screen, and stored for subsequent analysis.

Supplements were fed individually, with half the daily allocation given immediately following the a.m. milking, and the remainder fed immediately before (experiment 1) or after (experiment 2) the p.m. milking. Representative samples of each supplement were collected each day and bulked to provide a sample for each feed each week. Subsamples of approximately $100 \mathrm{~g}$ of fresh weight were oven-dried at $60^{\circ} \mathrm{C}$ for $72 \mathrm{~h}$, ground to pass through a 0.5 -mm screen, and stored for subsequent analysis. Representative samples of each supplement were also collected once per week and dried at $100^{\circ} \mathrm{C}$ to ensure an accurate measure of DMI of supplement. Where residues occurred, they were collected, separated into grain and pellets, and weighed. Subsamples of residues were dried at $100^{\circ} \mathrm{C}$ to determine DM contents.

Milk production of individual cows was measured at each milking before an experiment commenced, throughout the treatment period, and for $21 \mathrm{~d}$ after treatments finished in both experiments. In experiment 1, milk samples from the p.m. and a.m. milkings were taken from all cows on d $0,1,3,4,6,7,8,15,22,29$, $42,48,56$, and 63 to measure milk composition (protein, fat, lactose concentration) and SCC. A subsample of milk from cows within each treatment was bulked on each of these days to measure milk Se concentration. Five cows that did not consume the Se yeast pellets consistently throughout experiment 1 were excluded from the bulk milk samples for the relevant treatments. Samples from individual cows in the 0,8 , and $16 \mathrm{mg} /$ $\mathrm{d}$ of Se yeast treatments from d 22 and 42 were also analyzed for milk Se concentration. In experiment 2, milk samples were taken from all cows on d $0,3,6,9$, $13,15,21,22,28,29,35,36,45,51$, and 58 to measure bulk milk Se concentration on a treatment basis. A subsample of milk from individual cows in the 0,8 , and $16 \mathrm{mg} / \mathrm{d}$ of Se yeast treatments from d 21 and 35 were also analyzed for milk Se concentration. In addition, individual cow samples from d $0,9,15,21,28,35,45$, 51 , and 58 were analyzed for milk composition and SCC. Finally, BW and BCS (according to the 8-point scale of Earle, 1976) were recorded each week after the a.m. milking.
Blood samples were taken from the tail vein of each cow in the morning during wk 3,6, and 9 in both experiments for analysis of plasma (experiment 1) and whole blood (experiment 2) Se concentrations. Fecal samples were collected from the rectum of all cows on $\mathrm{d} 18$ and 39 in both experiments. For each treatment, a composite sample was created for each of these days by bulking material from cows on an equal DM basis. Muscle tissue biopsies were taken from the semitendinosus muscle of all cows on $d 17,38$, and 59 with a biopsy drill fitted with a 14-gauge $\times 38$-mm needle, removing approximately $150 \mathrm{mg}$ of tissue. Before the biopsy was taken, the site was cleaned with alcohol, and after tissue removal, the site was sprayed with antibiotic. The area from which the biopsy was taken was desensitized with an injection of local anesthetic [2.5 $\mathrm{mL}$ of Ilium Lignocaine 20 , active ingredient lignocaine hydrochloride (20 $\mathrm{mg} / \mathrm{mL}$ ); Troy Laboratories Pty. Ltd., Smithfield, New South Wales, Australia]. All biopsy samples were analyzed for Se concentration.

\section{Analytical Methods}

Samples of grain and pellets were analyzed for DM, nitrogen (by combustion with an FP-428 instrument, Leco Australia Pty. Ltd., Baulkham Hills, New South Wales, Australia), NDF (Van Soest et al., 1991), in vitro DM digestibility (IVDMD; Tilley and Terry, 1963), and Se concentration (see below). Metabolizable energy $(\mathrm{MJ} / \mathrm{kg}$ of $\mathrm{DM})$ was calculated by using $0.17 \times \mathrm{IVDMD}$ (\%) - 2.0 (Standing Committee on Agriculture, 1990), and $\mathrm{CP}$ was calculated as nitrogen $\times 6.25$. Samples of pasture were analyzed as for the supplements, except that IVDMD was determined by a pepsin-cellulase technique (Clarke et al., 1982). Milk samples were analyzed for protein, fat, and lactose concentrations with an infrared milk analyzer, as was SCC (Foss 4000/5000 Combi, Foss Electric, Hillerød, Denmark).

Total Se in milk, feed, fecal, plasma and whole blood, and muscle samples was determined after digesting subsamples in a mixture of nitric and perchloric acids by using test tubes fitted with reflux funnels in an electrically heated digestion block. In the end stage of the digestion process, hydrochloric acid was added to the tubes to reduce selenium(V) to selenium(III), with the final matrix being 30\% hydrochloric acid. The digestates were diluted (to $20 \mathrm{~mL}$ final volume) and analyzed by inductively coupled plasma mass spectrometry/vapor generation. Duplicate samples were included at 3 to 4 per 100 samples, and reproducibility was at least $90 \%$. Both standard reference material and laboratory control samples were carried through all analyses. The standard reference materials were National Institute of Standards and Technology standard 1549 
(nonfat milk powder) and standard 1577b (bovine liver). "In-house"-prepared laboratory control samples were ovine kidney, chicken meat, and nonfat milk powder. In each run, 2 randomly selected samples were spiked, with acceptable recoveries being between 80 and $120 \%$. Three blanks (empty tubes) were also included in the digestion and analysis process in each run. For muscle, additional tuning was performed on the inductively coupled plasma mass spectrometry/vapor generation system to increase sensitivity.

\section{Statistical Analysis and Calculations}

Treatment responses for animal variables were compared by repeated measures analysis of covariance (Genstat 8, Lawes Agricultural Trust, 2005) with a 2 $\times 5$ factorial with triticale (low- and high-Se concentration) and amount of Se yeast (nominally $0,4,8,12$, and $16 \mathrm{mg}$ of Se/d) as factors. Data for individual cows were used, and significant differences between factors were established at $P=0.05$. The same analysis was undertaken in which individual cow data were available for milk, blood, and muscle tissue Se concentrations, but without the use of covariates. For the 5 cows that did not consume their supplements, the Genstat 8 (Lawes Agricultural Trust, 2005) program estimated missing values based on data from other animals in a group.

Relationships between milk Se concentration (Y; $\mu \mathrm{g} /$ $\mathrm{kg}$ ), or milk Se output (Y; mg/d), and total Se intake (X; $\mathrm{mg} / \mathrm{d}$ ) were examined by using group data in stepwise regression analyses in Genstat 8 (Lawes Agricultural Trust, 2005) according to the following model:

$$
\begin{aligned}
\mathrm{Y}= & \mathrm{a}+\mathrm{b} \cdot \mathrm{X}+\mathrm{c} \cdot \mathrm{X}^{2}+\mathrm{d} \cdot \text { experiment } \\
& +\mathrm{e} \cdot \text { grain }+\mathrm{f} \cdot \text { interactions }
\end{aligned}
$$

where "experiment" is a pseudovariable to distinguish between experiments $1(+1)$ and $2(+2)$; "grain" is a pseudovariable to distinguish between low-Se $(-1)$ and high-Se $(+1)$ triticale grain; and interactions refers to the first-order interactions between each of the variables. A variable was included in a regression only if it was significant at $P<0.05$. Average plateau data during the treatment period were used, which were defined as being from d 15 in experiment 1 and from d 7 in experiment 2 . The same model was used, in which muscle Se concentration was the dependent variable, but separate regressions were generated for wk 3,6 , and 9.

Fecal output was calculated by using estimated total DMI and the IVDMD of dietary components. The DMI of pasture was estimated by using Diet Check (Heard et al., 2004b), and total DMI was calculated by using this value and measured supplement intakes. Fecal Se excretion was calculated from estimated fecal DM output and the Se concentration of the composite feces grab samples.

\section{RESULTS}

\section{Feeds and Intake}

In experiment 1 , the pasture mass $( \pm \mathrm{SD})$ was 5.2 $( \pm 0.57)$ tonne of $\mathrm{DM} / \mathrm{ha}$ and daily pasture allowance was $39( \pm 2.6) \mathrm{kg}$ of $\mathrm{DM} / \mathrm{cow}$. In experiment 2 , the pasture mass was $4.0( \pm 0.26)$ tonne of $\mathrm{DM} / \mathrm{ha}$ and daily pasture allowance was $37( \pm 2.1) \mathrm{kg}$ of $\mathrm{DM} / \mathrm{cow}$. The ME of pasture consumed was similar in both experiments, but $\mathrm{CP}, \mathrm{NDF}$, and Se concentrations were slightly greater in experiment 2 (Table 1). The ME and NDF concentrations of the 2 triticale grains and the $5 \mathrm{Se}$ yeast pellets were similar, but the $\mathrm{CP}$ concentrations of the grain were less than those of the Se yeast pellets. The low- and high-Se grains were consistent in their difference in average Se concentration between experiments (Table 1), but the coefficients of variation $(\mathbf{C V})$ within a grain were between 11 and $23 \%$, indicating the existence of considerable variation. The targeted Se concentrations in the Se yeast pellets were generally achieved (Table 1), but again there was variation within a pellet, with $\mathrm{CV}$ ranging from 3 to $13 \%$; however, this variation was not related to treatment.

Average intakes of DM and Se from grain and pellets were similar in both experiments (Table 2); however, the pattern of intake of the grain and pellets varied between experiments (Figure 1). In experiment 1, cows did not consume all of their grain or pellets until approximately d 15 of the experiment, whereas in experiment 2 , this occurred almost immediately. The estimated DMI of pasture averaged approximately 13.0 and 12.5 $\mathrm{kg} / \mathrm{cow}$ in experiments 1 and 2 , respectively, and constituted approximately $70 \%$ of total DMI.

\section{Animal Production}

Repeated measures analyses indicated that time was not a significant factor in either experiment; hence, only means for the whole experimental period are given in Table 3. There were no effects of grain type or Se yeast treatment on any aspect of animal production in either experiment. The exception was a small increase in milk lactose concentration in experiment 2 as the amount of Se yeast increased, but there was no effect on lactose production.

\section{Selenium Concentrations and Output}

Experiment 1. Selenium concentrations in milk plateaued after $15 \mathrm{~d}$ of supplementation, and then re- 


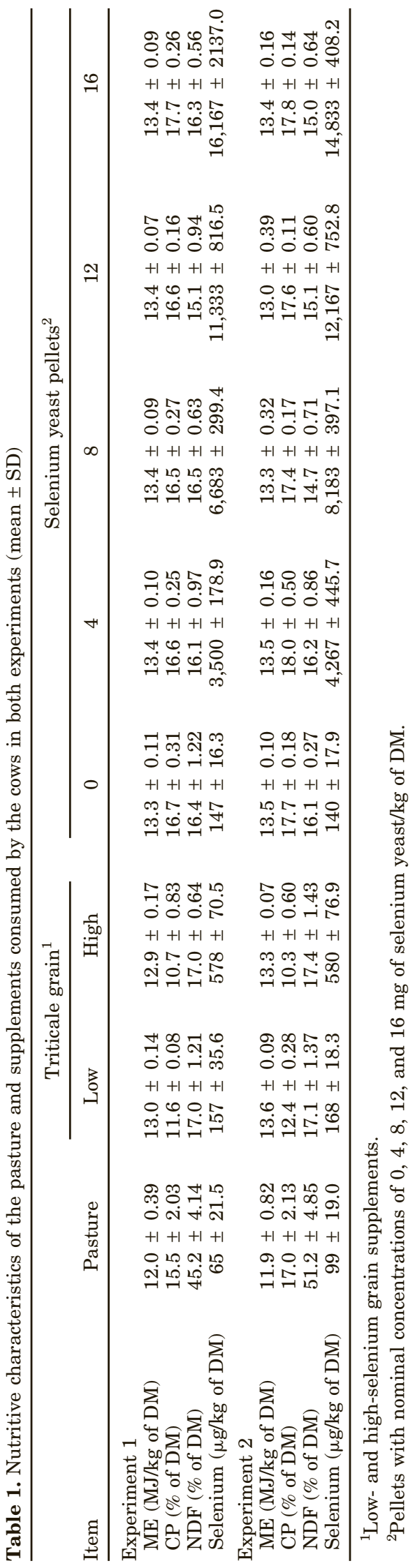

mained at plateau concentrations until treatments ceased (Figure 2A). After supplementation with grain and Se yeast had ceased, concentrations declined rapidly to approach pretreatment values. When individual cow data for wk 3 and 6 were analyzed, Se yeast increased milk Se concentration across the range, but the Se in triticale had no effect at the greatest concentration of Se yeast (Table 4). Between-cow variation in milk Se concentration within treatments was similar across treatments, with $\mathrm{CV}$ averaging 10.1, 12.1, and $12.0 \%$ for the 0,8 , and $16 \mathrm{mg} / \mathrm{d}$ of Se yeast treatments, respectively. Plasma Se concentrations changed more slowly than did milk Se concentrations. They increased from wk 3 to 6 (89 vs. $110 \mu \mathrm{g} / \mathrm{kg}$, on average; SE of the difference $=1.5$ ) and only returned to wk 3 concentrations 3 wk after treatments had ceased $(87 \mu \mathrm{g} / \mathrm{kg})$. Plasma Se concentrations were consistently different because of the triticale treatment, and Se yeast increased plasma Se concentrations up to the second highest concentration of Se yeast (Table 4). Muscle Se concentrations increased with the amount of Se in the diet regardless of its origin, but were slower to change than those of plasma, with muscle Se concentrations $3 \mathrm{wk}$ after the cessation of treatment being no different from those recorded after $6 \mathrm{wk}$ of Se supplementation (Table 4). Mean fecal Se concentrations were $0.2,0.6,0.8,1.2$, and $1.5 \mathrm{mg} / \mathrm{kg}$ of DM when low-Se triticale was fed, and were $0.5,0.7,1.1,1.2$, and $1.5 \mathrm{mg} / \mathrm{kg}$ of $\mathrm{DM}$ when high-Se triticale was fed to cows supplemented with 0 , $4,8,12$, and $16 \mathrm{mg}$ of Se yeast/d, respectively.

Experiment 2. Milk Se concentrations reached plateau values within a week of commencing supplementation, and these were maintained for the rest of the treatment period (Figure 2B). When milk samples from individual cows during wk 3 and 6 were examined, Se concentrations increased with both Se yeast and Se in triticale (Table 4 ). In contrast to experiment 1 , betweencow variation in milk Se concentration decreased as the concentration of Se yeast increased. For the 0,8 , and $16 \mathrm{mg} / \mathrm{d}$ of Se yeast treatments, CV averaged 19.8, 14.1, and $9.7 \%$, respectively, principally because of greater increases in means relative to SD. Whole blood Se concentrations rose between wk 3 and 6 (176 vs. $212 \mu \mathrm{g} /$ $\mathrm{kg}$, on average; $\mathrm{SE}$ of the difference $=2.4$ ), but had not returned to wk 3 concentrations $3 \mathrm{wk}$ after treatments had ceased (192 $\mu \mathrm{g} / \mathrm{kg})$. Whole blood Se concentrations generally increased consistently with both triticale and Se yeast treatments (up to the second highest concentration), and muscle Se concentrations followed similar tends (Table 4). Finally, mean fecal Se concentrations were $0.3,0.8,1.1,1.3$, and $1.7 \mathrm{mg} / \mathrm{kg}$ of $\mathrm{DM}$ when lowSe triticale was fed, and were $0.5,0.9,1.3,1.5$, and 1.8 $\mathrm{mg} / \mathrm{kg}$ of DM when high-Se triticale was fed to cows 
Table 2. Estimated daily DMI and selenium intake for all treatments averaged across whole experimental periods

\begin{tabular}{|c|c|c|c|c|c|c|c|c|c|c|}
\hline \multirow[b]{3}{*}{ Item } & \multicolumn{10}{|c|}{ Selenium yeast pellets ${ }^{1}$} \\
\hline & \multicolumn{5}{|c|}{ Low-selenium triticale grain ${ }^{2}$} & \multicolumn{5}{|c|}{ High-selenium triticale grain ${ }^{2}$} \\
\hline & 0 & 4 & 8 & 12 & 16 & 0 & 4 & 8 & 12 & 16 \\
\hline \multicolumn{11}{|c|}{ Experiment 1} \\
\hline \multicolumn{11}{|c|}{ DMI (kg/cow) } \\
\hline Grain & 3.91 & 3.73 & 3.80 & 3.78 & 3.93 & 3.92 & 3.94 & 3.82 & 3.92 & 3.89 \\
\hline Pellets & 1.00 & 0.94 & 0.94 & 0.99 & 0.98 & 1.01 & 1.01 & 0.99 & 1.02 & 0.98 \\
\hline Pasture & 12.6 & 12.6 & 13.4 & 13.0 & 12.7 & 13.3 & 13.4 & 13.4 & 13.2 & 12.7 \\
\hline Total & 17.5 & 17.3 & 18.1 & 17.8 & 17.6 & 18.2 & 18.4 & 18.2 & 18.1 & 17.6 \\
\hline \multicolumn{11}{|c|}{ Selenium intake (mg/cow) } \\
\hline Grain & 0.61 & 0.59 & 0.60 & 0.59 & 0.62 & 2.27 & 2.28 & 2.21 & 2.27 & 2.25 \\
\hline Pellets & 0.15 & 3.29 & 6.28 & 11.22 & 15.84 & 0.15 & 3.54 & 6.62 & 11.56 & 15.84 \\
\hline Pasture & 0.82 & 0.82 & 0.87 & 0.85 & 0.83 & 0.87 & 0.87 & 0.87 & 0.86 & 0.83 \\
\hline Total & 1.58 & 4.70 & 7.75 & 12.66 & 17.29 & 3.28 & 6.68 & 9.70 & 14.68 & 18.92 \\
\hline \multicolumn{11}{|c|}{ Experiment 2} \\
\hline \multicolumn{11}{|c|}{ DMI (kg/cow) } \\
\hline Grain & 3.96 & 3.96 & 3.95 & 3.94 & 3.94 & 3.92 & 3.90 & 3.93 & 3.93 & 3.90 \\
\hline Pellets & 1.06 & 1.06 & 1.03 & 1.02 & 1.01 & 1.06 & 1.06 & 1.03 & 1.03 & 1.03 \\
\hline Pasture & 12.8 & 12.1 & 12.6 & 12.8 & 12.1 & 12.6 & 12.2 & 12.7 & 12.5 & 12.7 \\
\hline Total & 17.8 & 17.1 & 17.6 & 17.8 & 17.1 & 17.6 & 17.2 & 17.7 & 17.5 & 17.6 \\
\hline \multicolumn{11}{|c|}{ Selenium intake (mg/cow) } \\
\hline Grain & 0.67 & 0.67 & 0.66 & 0.66 & 0.66 & 2.27 & 2.26 & 2.28 & 2.28 & 2.26 \\
\hline Pellets & 0.15 & 4.52 & 8.43 & 12.41 & 14.98 & 0.15 & 4.52 & 8.43 & 12.53 & 15.28 \\
\hline Pasture & 1.27 & 1.20 & 1.25 & 1.27 & 1.20 & 1.25 & 1.21 & 1.26 & 1.24 & 1.26 \\
\hline Total & 2.08 & 6.39 & 10.34 & 14.34 & 16.84 & 3.67 & 7.99 & 11.96 & 16.05 & 18.80 \\
\hline
\end{tabular}

${ }^{1}$ Pellets with nominal concentrations of $0,4,8,12$, and $16 \mathrm{mg}$ of selenium yeast/kg of DM.

${ }^{2}$ Low- and high-selenium grain supplements.

supplemented with $0,4,8,12$, and $16 \mathrm{mg}$ of Se yeast/ d, respectively.

Relationships Between Se Input and Output. There were significant positive, linear relationships between total Se intake and the concentration of Se in milk, and these were similar in both experiments (Table

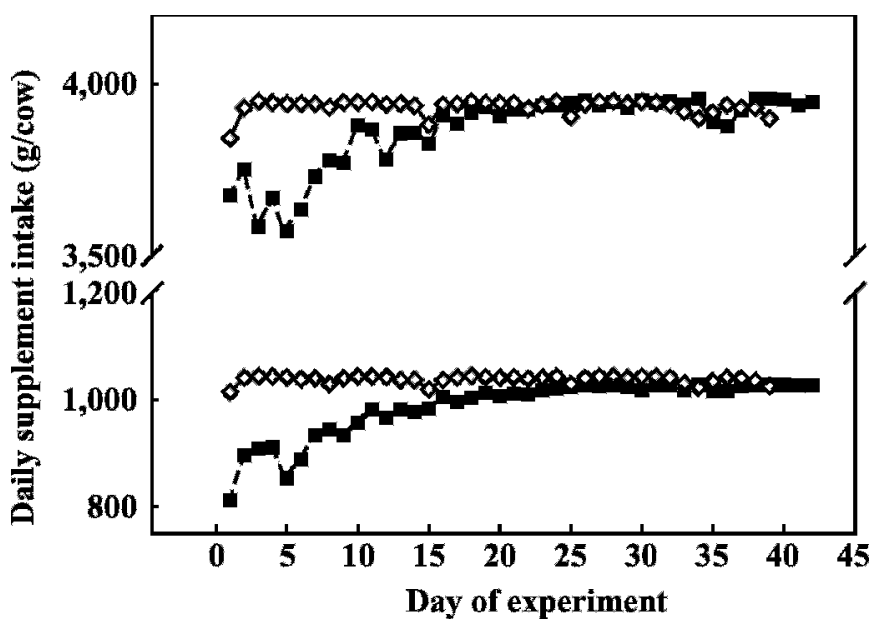

Figure 1. Change in intake of pellets containing selenium yeast (bottom half of the graph) and triticale grain (top half of the graph), averaged across treatments, during experiment $1(\square)$ and experiment $2(\diamond)$.
5 and Figure 3). Hence, the Se output in milk in experiment 1 was greater than that in experiment 2 (Figure 4 ) because of the difference in milk yield between experiments (Table 3 ). The regression equation relating total Se intake $(\mathrm{mg} / \mathrm{d})$ and milk Se output $(\mathrm{mg} / \mathrm{d})$ in the experiments (experiment; experiment $1=+1$, experiment $2=$ $+2)$ was

$$
\begin{gathered}
\text { milk Se output }=0.12( \pm 0.066) \\
+0.32( \pm 0.010) \text { total Se intake }-0.11( \pm 0.005) \\
\text { experiment } \times \text { total Se intake } \\
100 \mathrm{R}^{2}=98.6(P<0.001) ; \\
\mathrm{RSD}=0.14 ; \mathrm{CV}=8.2 \% ; \mathrm{n}=20
\end{gathered}
$$

where RSD is the residual standard deviation.

The proportional output of Se in feces was similar at both stages of lactation, and it tended to decline with Se intake (Figure 4). Therefore, the estimated proportions of Se partitioned to destinations other than milk and feces increased with the amount of Se in the diet and were greater in experiment 2 than in experiment 1 (Figure 4). The relationships between total Se intake and muscle Se concentration were positive and linear (Table 5). In all relationships considered, the source of the additional Se had no influence on a relationship, 
Table 3. The effect of selenium supplementation on aspects of daily milk production, and BW and BCS averaged over the experimental periods in experiments 1 and 2

\begin{tabular}{|c|c|c|c|c|c|c|c|c|c|}
\hline \multirow[b]{2}{*}{ Item } & \multicolumn{6}{|c|}{ Selenium yeast pellets ${ }^{1}$} & \multicolumn{3}{|c|}{ Triticale grain $^{2}$} \\
\hline & 0 & 4 & 8 & 12 & 16 & $\mathrm{SED}^{3}$ & Low & High & $\mathrm{SED}^{3}$ \\
\hline \multicolumn{10}{|l|}{ Experiment 1} \\
\hline Milk yield (kg/cow) & 26.2 & 25.6 & 27.0 & 26.8 & 26.3 & 1.15 & 26.5 & 26.3 & 0.73 \\
\hline Milk fat (\%) & 3.52 & 3.68 & 3.27 & 3.44 & 3.52 & 0.154 & 3.40 & 3.57 & 0.098 \\
\hline Milk protein $(\%)$ & 3.03 & 3.04 & 2.93 & 2.92 & 3.05 & 0.093 & 2.99 & 2.99 & 0.059 \\
\hline Milk lactose (\%) & 5.01 & 4.95 & 4.94 & 4.97 & 5.06 & 0.088 & 5.02 & 4.95 & 0.056 \\
\hline Fat yield (kg/cow) & 0.93 & 0.95 & 0.89 & 0.91 & 0.94 & 0.049 & 0.90 & 0.95 & 0.031 \\
\hline Protein yield (kg/cow) & 0.80 & 0.78 & 0.79 & 0.77 & 0.81 & 0.033 & 0.79 & 0.79 & 0.021 \\
\hline Lactose yield (kg/cow) & 1.32 & 1.28 & 1.35 & 1.31 & 1.35 & 0.063 & 1.33 & 1.32 & 0.040 \\
\hline $\mathrm{SCC}(\times 1,000)$ & 72 & 105 & 178 & 59 & 39 & 60.7 & 66 & 114 & 38.4 \\
\hline $\mathrm{BW}(\mathrm{kg})$ & 534 & 539 & 539 & 534 & 526 & 9.1 & 532 & 538 & 5.8 \\
\hline $\mathrm{BCS}^{4}$ (units) & 4.3 & 4.4 & 4.4 & 4.2 & 4.3 & 0.09 & 4.3 & 4.4 & 0.06 \\
\hline \multicolumn{10}{|l|}{ Experiment 2} \\
\hline Milk yield (kg/cow) & 14.4 & 14.2 & 16.0 & 13.7 & 14.7 & 1.26 & 14.7 & 14.5 & 0.79 \\
\hline Milk fat $(\%)$ & 4.37 & 4.20 & 4.22 & 4.32 & 4.40 & 0.233 & 4.30 & 4.31 & 0.146 \\
\hline Milk protein (\%) & 3.79 & 3.79 & 3.77 & 3.90 & 3.84 & 0.073 & 3.81 & 3.82 & 0.046 \\
\hline Milk lactose (\%) & $4.85^{\mathrm{a}}$ & $4.78^{\mathrm{a}}$ & $4.95^{\mathrm{ab}}$ & $5.01^{b}$ & $5.00^{\mathrm{b}}$ & 0.070 & 4.90 & 4.93 & 0.044 \\
\hline Fat yield (kg/cow) & 0.64 & 0.61 & 0.67 & 0.60 & 0.65 & 0.048 & 0.64 & 0.63 & 0.030 \\
\hline Protein yield (kg/cow) & 0.56 & 0.57 & 0.59 & 0.54 & 0.58 & 0.036 & 0.58 & 0.56 & 0.023 \\
\hline Lactose yield ( $\mathrm{kg} / \mathrm{cow})$ & 0.71 & 0.69 & 0.80 & 0.71 & 0.74 & 0.068 & 0.73 & 0.73 & 0.042 \\
\hline $\mathrm{SCC}(\times 1,000)$ & 237 & 215 & 198 & 267 & 177 & 54.6 & 200 & 237 & 34.5 \\
\hline $\mathrm{BW}(\mathrm{kg})$ & 591 & 587 & 586 & 592 & 588 & 4.7 & 589 & 589 & 3.0 \\
\hline $\mathrm{BCS}^{4}$ (units) & 4.4 & 4.4 & 4.4 & 4.4 & 4.4 & 0.05 & 4.4 & 4.4 & 0.03 \\
\hline
\end{tabular}

${ }^{\mathrm{a}, \mathrm{b}}$ Means in a row for main effects with different superscripts differ $(P<0.05)$.

${ }^{1}$ Pellets with nominal concentrations of $0,4,8,12$, and $16 \mathrm{mg}$ of selenium yeast $/ \mathrm{kg}$ of DM.

${ }^{2}$ Low- and high-selenium grain supplements.

${ }^{3} \mathrm{SED}=$ standard error of difference.

${ }^{4}$ On the 1- to 8-point scale of Earle (1976).

including those for plasma and whole blood (relationships not shown). In addition, Se concentration relationships were not affected by interactions between any of the independent variables.

\section{DISCUSSION}

The hypothesis that the response in milk, blood, and tissue Se concentrations to additional dietary Se would not be affected by whether the Se was supplied by the basal diet or from Se yeast was confirmed in both experiments for total Se intakes up to $19 \mathrm{mg} / \mathrm{d}$. Both sources of additional Se appeared to be equally effective in elevating Se concentrations. This occurred in spite of there being a tendency toward a lack of effect of grain Se concentration on milk Se concentration at the greatest amounts of Se yeast. At $4 \mathrm{mg}$ of Se yeast/d, the basal diet provided approximately 30 and $45 \%$ of total dietary Se when the diet included low- and high-Se triticale, respectively, but these values were only 10 and $18 \%$ at $16 \mathrm{mg}$ of Se yeast/d. The apparently smaller effect of Se in triticale with greater Se yeast supplementation is most likely a result of this dilution rather than because the Se from the basal diet became less biologically available at the higher inclusion rates of Se yeast. This notion is supported by the variation in Se concentration seen in Table 1, much of which is probably caused by the inherent variability associated with the analysis of Se.

The relationships between total Se intake and Se concentrations in milk presented here are different from those reported by Givens et al. (2004), Heard et al. (2004b), and Juniper et al. (2006; Figure 3), even though all studies used Se yeast from the same source. Differences in analytical techniques when determining Se concentrations may be an issue here, but cow and diet differences may also be implicated, although all cows were of Holstein origin and milk yields were similar. Givens et al. (2004) and Juniper et al. (2006) fed TMR in intensive feeding systems with cows at various stages of lactation, and Heard et al. (2004b) conducted their research with grazing dairy cows in early lactation. We acknowledge that seasonal effects on the pasture available for grazing and stage of lactation are confounded in the present study, with the experiments not being specifically designed to test for these factors. The similarities in nutritive characteristics and DMI of the various feeds in both of our experiments, however, lead us to suggest that it was principally stage of lactation, and the associated differences in milk and milk protein yields, that differentiated our 2 studies. There was little difference in the relationships between milk 

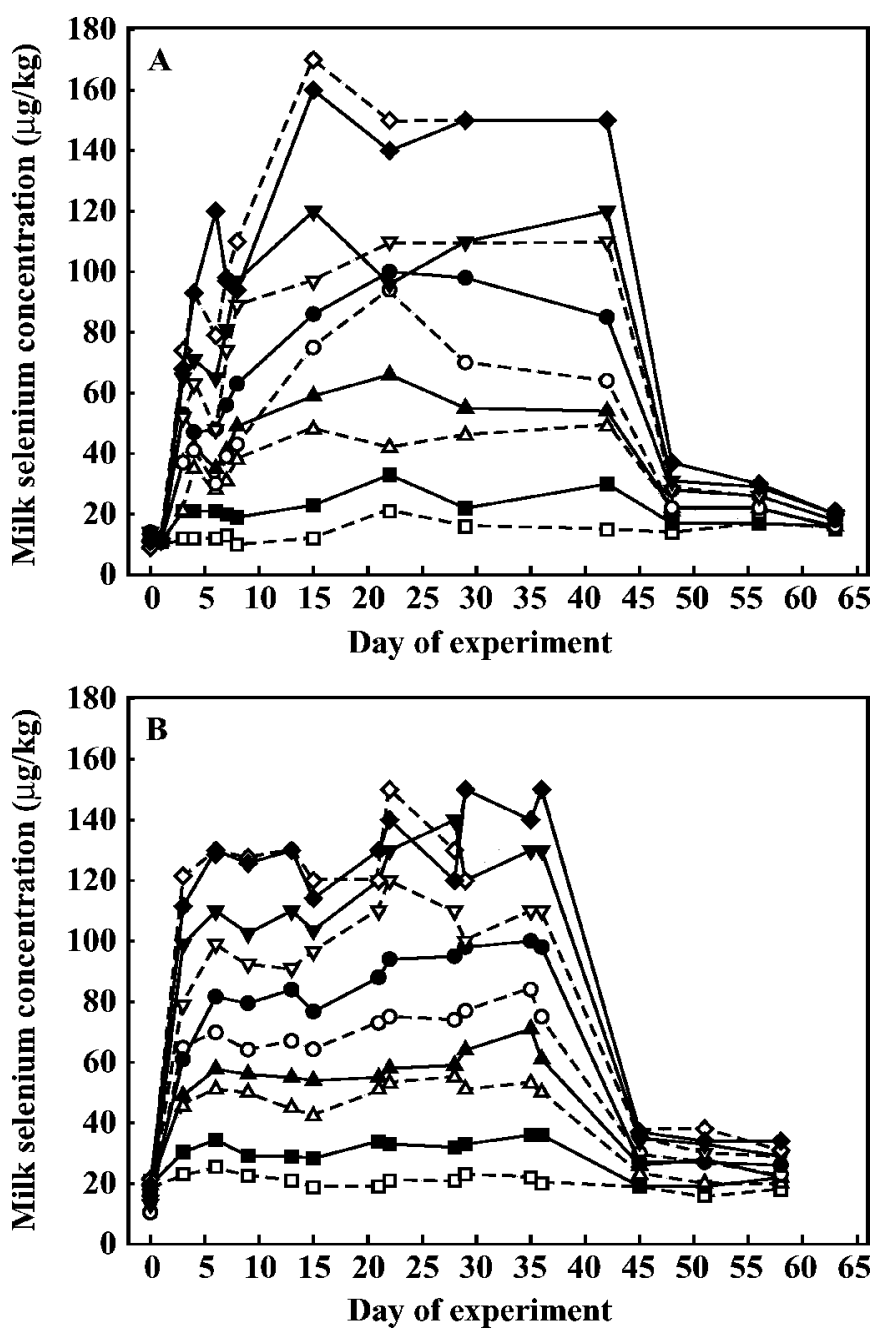

Figure 2. Effect of Se from Se yeast ( $\square$, $\mathbf{\square}: 0 \mathrm{mg}$ of Se yeast treatment; $\triangle, \mathbf{\Delta}: 4 \mathrm{mg}$ of Se yeast treatment; $\bigcirc, \bullet: 8 \mathrm{mg}$ of Se yeast treatment; $\nabla, \boldsymbol{\nabla}: 12 \mathrm{mg}$ of Se yeast treatment; $\diamond, \diamond: 16 \mathrm{mg}$ of Se yeast treatment) and triticale grain (low Se concentration: open symbols; high Se concentration: full symbols) on milk Se concentrations in A) experiment 1 and B) experiment 2 .

Se concentration and Se intake between the 2 experiments (as described in Table 5 and demonstrated in Figure 3), but the output of Se in milk differed greatly because of the greater milk production in early lactation. Although we suggest that stage of lactation is the principal difference between our experiments, we believe there is still a need for further clarification of the roles of diet and stage of lactation on milk Se concentration.

To be able to provide high-Se milk for the commercial production of health ingredients or products, it is important to be able to predict the time taken to reach plateau concentrations after the commencement of supplementation with high-Se feeds. In experiment 2 , and in previous reports with cows that had adequate Se intake (McIntosh and Royle, 2002; Heard et al., 2004b), milk Se concentrations peaked at approximately $7 \mathrm{~d}$ after the introduction of Se yeast. The results of experiment 1 illustrate the importance of cows consuming the desired amount of supplement. With experiments 1 and 2 coinciding with early and late lactation, respectively, we suggest that, on commercial farms where seasonal calving is practiced, it would be best to implement strategies to produce high-Se milk in mid to late lactation to avoid issues with freshly calved cows that tend to have variable DMI.

Effects of Se supplementation on animal production in our experiments were not anticipated. The estimated ME intakes were not different between treatments, and several variables clearly indicate the adequacy of the Se status of the cows we used. It is principally when Se supplements are fed to Se-deficient cows that production responses can be expected. Witchel et al. (1994) suggested cows grazing pasture with less than $30 \mu \mathrm{g}$ of Se/kg of DM would have inadequate Se intakes, whereas Caple et al. (1980) considered that pasture with $50 \mu \mathrm{g}$ of Se/kg of DM would provide adequate Se. The Se concentrations in our pastures and supplements were always greater than $60 \mu \mathrm{g}$ of $\mathrm{Se} / \mathrm{kg}$ of DM, indicating sufficiency of Se in the basal diet. Furthermore, blood Se concentrations of greater than $21 \mu \mathrm{g}$ of Se/kg are generally considered to be indicative of adequate Se in lactating dairy cows (Witchel et al., 1994; Thompson et al., 1998; Grace et al., 2001). A blood Se concentration of $21 \mu \mathrm{g}$ of Se/kg is associated with a milk Se concentration of $4 \mu \mathrm{g}$ of Se/kg according to a regression developed by Grace et al. (2001). The minimum average milk Se concentration before or during either experiment was approximately 12 to $13 \mu \mathrm{g} / \mathrm{kg}$, and concentrations of Se in whole blood measured in experiment 2 were in excess of $100 \mu \mathrm{g}$ of Se/kg.

In experiment 1 , plasma Se concentrations increased with dietary Se supplementation up to approximately $12 \mathrm{mg}$ of Se yeast/d, beyond which there was no further increase regardless of the source of Se. The results were similar for whole blood Se in experiment 2, although blood Se was higher than in plasma. Kim and Mahan (2001) suggest that, at least for pigs, red blood cell Se is a better indicator of Se status than plasma Se, particularly for organic forms of Se, for which no plateau in the dose-response curve was apparent when up to $40 \mathrm{mg} / \mathrm{kg}$ of feed was consumed daily. Apparently, Se can be incorporated into red blood cells only during erythropoiesis, and because this process occurs slowly, there will be a lag in blood Se response following changes in Se supplementation (Thompson et al., 1980). After treatments ceased on d 42 or 39 in the present experiments, milk Se concentration from cows receiving 
Table 4. Summary statistics of the effect of $6 \mathrm{wk}$ of selenium treatment on the concentrations of selenium ( $\mu \mathrm{g} / \mathrm{kg}$ ) in milk and blood or plasma, and in muscle biopsies, in experiments 1 and 2

\begin{tabular}{|c|c|c|c|c|c|c|c|c|c|}
\hline Item & \multicolumn{6}{|c|}{ Selenium yeast pellets ${ }^{1}$} & \multicolumn{3}{|c|}{ Triticale grain $^{2}$} \\
\hline \multicolumn{10}{|l|}{ Experiment 1} \\
\hline Low selenium grain & $13^{\mathrm{a}}$ & & $68^{\mathrm{c}}$ & & $131^{\mathrm{e}}$ & \multirow[t]{2}{*}{5.6} & & & \\
\hline High selenium grain & $27^{\mathrm{b}}$ & & $88^{\mathrm{d}}$ & & $129^{\mathrm{e}}$ & & & & \\
\hline \multicolumn{10}{|l|}{ Plasma samples collected from individual cows } \\
\hline Week 3 & $44^{\mathrm{a}}$ & $85^{\mathrm{b}}$ & $88^{\mathrm{b}}$ & $123^{\mathrm{d}}$ & $107^{\mathrm{c}}$ & 4.1 & $83^{\mathrm{a}}$ & $95^{\mathrm{b}}$ & 3.2 \\
\hline \multicolumn{10}{|l|}{ Muscle biopsy samples collected from individual cows } \\
\hline Week 3 & $97^{\mathrm{a}}$ & $114^{\mathrm{ab}}$ & $130^{\mathrm{bc}}$ & $147^{\mathrm{cd}}$ & $158^{\mathrm{d}}$ & \multirow[t]{3}{*}{9.0} & $120^{\mathrm{a}}$ & $139^{\mathrm{b}}$ & \multirow[t]{3}{*}{5.7} \\
\hline Week 6 & $103^{\mathrm{a}}$ & $133^{\mathrm{b}}$ & $166^{\mathrm{c}}$ & $179^{\mathrm{c}}$ & $208^{\mathrm{d}}$ & & $151^{\mathrm{a}}$ & $164^{\mathrm{b}}$ & \\
\hline Week 9 & $104^{\mathrm{a}}$ & $143^{\mathrm{b}}$ & $162^{\mathrm{c}}$ & $181^{\mathrm{d}}$ & $208^{\mathrm{e}}$ & & $151^{\mathrm{a}}$ & $168^{\mathrm{b}}$ & \\
\hline \multicolumn{10}{|l|}{ Experiment 2} \\
\hline Average of individual cow milk data collected during wk 3 and 6 & $27^{\mathrm{a}}$ & & $91^{\mathrm{b}}$ & & $138^{\mathrm{c}}$ & 4.0 & $79^{\mathrm{a}}$ & $92^{\mathrm{b}}$ & 3.3 \\
\hline Week 3 & $140^{\mathrm{a}}$ & $158^{\mathrm{ab}}$ & $173^{\mathrm{b}}$ & $175^{\mathrm{b}}$ & $173^{\mathrm{b}}$ & \multirow[t]{3}{*}{11.9} & 159 & 169 & \multirow[t]{3}{*}{7.5} \\
\hline Week 6 & $142^{\mathrm{a}}$ & $171^{\mathrm{b}}$ & $208^{\mathrm{c}}$ & $243^{\mathrm{d}}$ & $233^{\mathrm{d}}$ & & 191 & 207 & \\
\hline Week 9 & $126^{\mathrm{a}}$ & $177^{\mathrm{b}}$ & $176^{\mathrm{b}}$ & $214^{\mathrm{c}}$ & $225^{\mathrm{c}}$ & & 177 & 190 & \\
\hline
\end{tabular}

${ }^{\mathrm{a}-\mathrm{e}}$ Means in a row for main effects, or for interactions, with different superscripts differ $(P<0.05)$.

${ }^{1}$ Pellets with nominal concentrations of $0,4,8,12$, and $16 \mathrm{mg}$ of selenium yeast $/ \mathrm{kg}$ of DM.

${ }^{2}$ Low- and high-selenium grain supplements.

${ }^{3} \mathrm{SED}=$ standard error of difference.

Se yeast declined to near pre-experimental concentrations within a week, although small effects were still apparent 3 wk after the cessation of supplementation. The plasma and blood Se concentrations declined much more slowly, indicating a continuing influx into the circulatory system of Se from body tissues. Furthermore, although milk is synthesized and removed daily, the turnover of plasma Se-protein and red blood cells is a much slower process.
The NRC (2005) recommends that the maximum tolerable amount of Se for ruminants is $5 \mathrm{mg}$ of Se/kg of DM. Based on this figure, a high-producing dairy cow should be able to consume up to $100 \mathrm{mg}$ of Se/d for extended periods without developing symptoms of toxicity. In developing feeding systems that include significant amounts of organic Se supplements to produce high-Se products, it is important to consider changes in indicators of animal health and accumulation in tissues

Table 5. Regression relationships between total selenium intake $(\mathrm{mg} / \mathrm{d})$ and selenium concentration in milk or the selenium concentration in muscle biopsies

\begin{tabular}{|c|c|c|c|c|}
\hline Dependent variable & Significant regression equation ${ }^{1}$ & $100 R^{2}$ & $\mathrm{RSD}^{2}$ & CV \\
\hline \multicolumn{5}{|c|}{ Muscle Se concentration $(\mu \mathrm{g} / \mathrm{kg})$} \\
\hline At wk 3 & $65.7( \pm 9.34)+3.2( \pm 0.47)$ total selenium intake $+31.8( \pm 5.28)$ experiment & $\begin{array}{c}84.1 \\
(P<0.001)\end{array}$ & 11.8 & 8.1 \\
\hline At wk 6 & $57.0( \pm 10.40)+6.6( \pm 0.52)$ total selenium intake $+35.6( \pm 5.89)$ experiment & $\begin{array}{c}92.4 \\
(P<0.001)\end{array}$ & 13.1 & 7.3 \\
\hline
\end{tabular}

\footnotetext{
${ }^{1}$ Only significant $(P<0.05)$ terms have been included. Total selenium intake $(\mathrm{mg} / \mathrm{kg}$ of $\mathrm{DM})$ includes selenium from pasture, grain, and selenium yeast. The term "experiment" is a pseudovariable to distinguish between experiment $1(+1)$ and experiment $2(+2)$. Treatment means were used $(\mathrm{n}=20)$.

${ }^{2} \mathrm{RSD}=$ residual standard deviation of regression equation.

${ }^{3}$ Weeks 3 to 6 in experiment 1 and wk 2 to 6 in experiment 2 .
} 


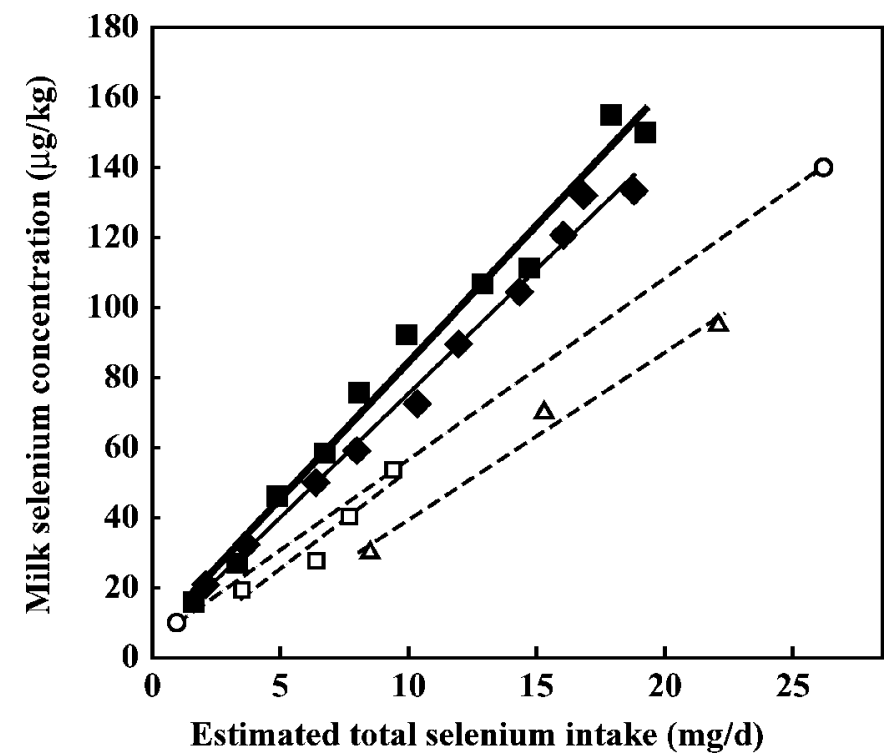

Figure 3. Relationships between total Se intake and the concentration of Se in milk in experiment 1 ( $\square$ : average of d 15 to 42 ) and experiment 2 ( : average of $d 9$ to 36). Results from other experiments ( $\triangle$ : Givens et al., 2004; ○: Heard et al., 2004a; $\square$ : Juniper et al., 2006).

other than milk, and to establish the quantities excreted in urine and feces. The efficiency of incorporation of Se into milk, as described by the proportions of intake partitioned to various destinations (Figure 4), was greater in experiment 1 than in experiment 2 , presumably because of the greater output of milk and milk protein by the cows in experiment 1 . Supplementation with organic Se does lead to accumulation of Se in muscle and other organs, as well as in milk. Only limited data are available on accumulation of Se from Se yeast in tissues of lactating dairy cows, and this is only when small amounts have been fed (Ortman and Pehrson, 1997). The research reported here clearly indicates that, at least in skeletal muscle, concentrations increase in response to increases in Se from the basal diet and from Se yeast. The results also clearly indicate that the elimination of the accumulated Se from muscle takes longer than $3 \mathrm{wk}$ after supplementation has ceased. The implications of this for both continued onfarm production of high-Se milk and its management at the factory level need to be investigated.

\section{CONCLUSIONS}

Supplementation of grazing dairy cows with increasing amounts of Se led to similar linear increases in milk Se concentrations in both experiments, regardless of whether the increase in Se intake was from Se in the triticale supplement or from the Se yeast. With the nutritive characteristics and intakes of the various
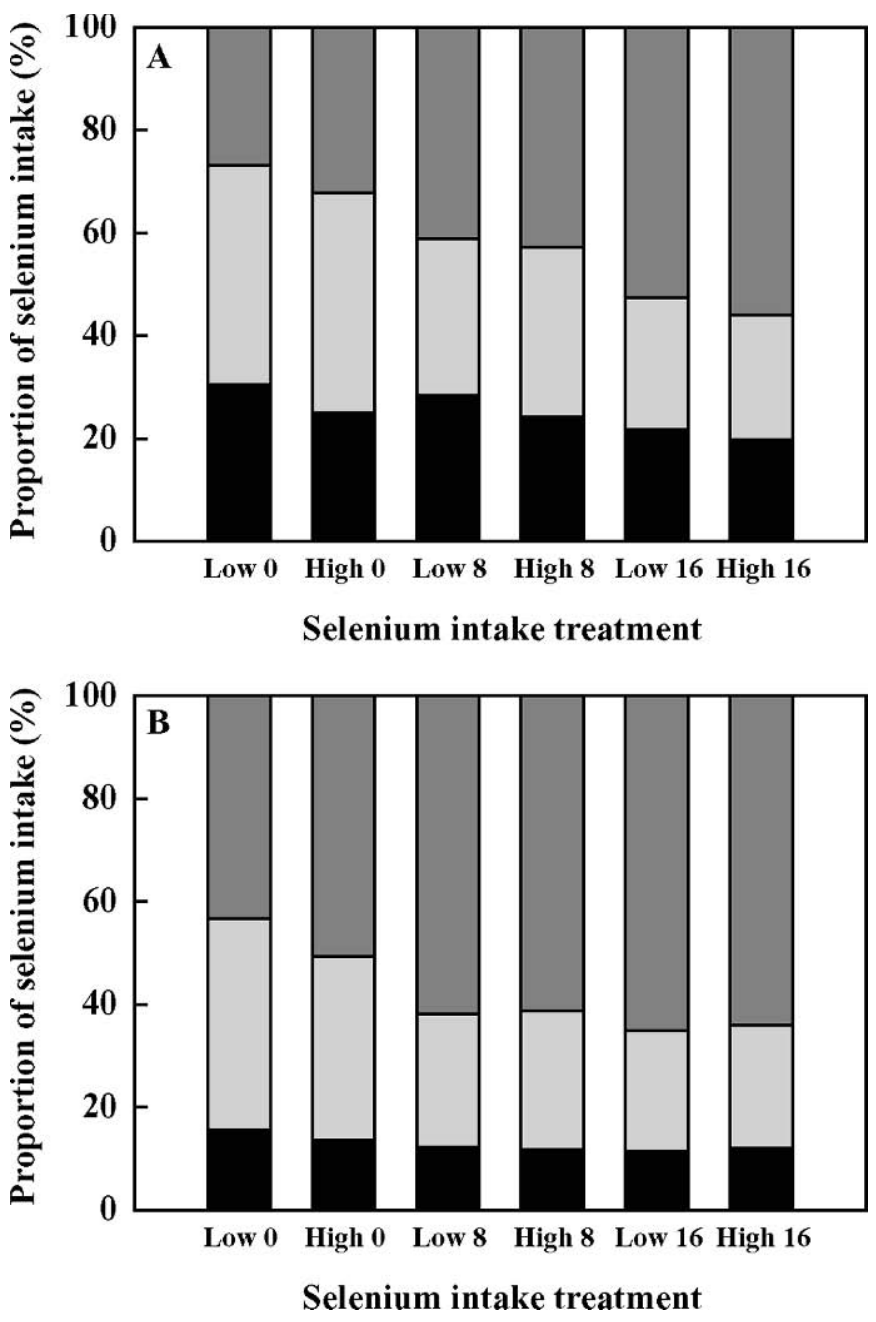

Figure 4. Effect of Se from Se yeast (0 mg of Se yeast treatment; $8 \mathrm{mg}$ of Se yeast treatment; $16 \mathrm{mg}$ of Se yeast treatment) and triticale grain (low- and high-Se concentrations) on the proportions of Se in milk (black), feces (light gray), and unknown (dark gray) destinations in dairy cows in A) experiment 1 and B) experiment 2.

feeds being similar in the experiments reported here, we suggest it was principally the greatly different DIM, and the associated differences in milk and milk protein yields, that differentiated the 2 experiments. Therefore, it appears that stage of lactation is unlikely to affect the relationship between milk Se concentration and Se intake. If high-Se products are to be produced for human nutrition, it is important to be able to develop feeding systems that produce milk with consistent and predictable Se concentrations so that products can consistently meet specifications. The results indicate that this objective is achievable.

\section{ACKNOWLEDGMENTS}

Funding provided by Tatura Milk Industries Pty. Ltd., Alltech Biotechnology Pty. Ltd., the Geoffrey Gar- 
diner Dairy Foundation (Melbourne, Australia), and the Department of Primary Industries Victoria is acknowledged. Valuable technical assistance was provided by Marg Jenkin, Stuart Austin, Daryl Wilson, Shelly Warde, Rodger Medro, Ryan Cooper, and Allan Thorson and the farm staff at Department of Primary Industries Kyabram. Biometrics support was provided by Sorn Norng.

\section{REFERENCES}

Aro, A., G. Alfthan, P. Ekholm, P. Varo, W. T. J. Frankenberger, and R. A. Engberg. 1998. Effects of selenium supplementation of fertilizers on human nutrition and selenium status. Pages 8197 in Environmental Chemistry of Selenium. W. T. J. Frankenberger, ed. Marcel Dekker, New York, NY.

Binnerts, W. T. 1979. The selenium status of dairy cows in the Netherlands derived from milk and blood analysis. Neth. Milk Dairy J. 33:24-30.

Caple, I. W., K. A. Andrewartha, S. J. A. Edwards, and C. G. Halpin. 1980. An examination of the selenium nutrition of sheep in Victoria. Aust. Vet. J. 56:160-167.

Clarke, T., P. C. Flinn, and A. A. McGowan. 1982. Low-cost pepsincellulase assays for prediction of digestibility of herbage. Grass Forage Sci. 37:147-150.

Earle, D. F. 1976. A guide to scoring dairy cow condition. J. Agric. (Vic.) 74:228-231.

Earle, D. F., and A. A. McGowan. 1979. Evaluation and calibration of an automated rising plate meter for estimating dry matter yield of pasture. Aust. J. Exp. Agric. Anim. Husb. 19:337-343.

Givens, D. I., R. Allison, B. Cottrill, and J. S. Blake. 2004. Enhancing selenium content of bovine milk through alteration of the form and concentration of selenium in the diet of dairy cows. J. Sci. Food Agric. 84:811-817.

Grace, N. D., K. Ankenbauer-Perkins, A. M. Alexander, and R. M. Marchant. 2001. Relationship between blood selenium concentration or glutathione peroxidase activity, and milk selenium concentrations in New Zealand dairy cows. N. Z. Vet. J. 49:24-28.

Heard, J. W., D. C. Cohen, P. T. Doyle, W. J. Wales, and C. R. Stockdale. 2004a. Diet Check-A tactical decision support tool for feeding decisions with grazing dairy cows. Anim. Feed Sci. Technol. 112:177-194.

Heard, J. W., G. P. Walker, P. J. Royle, G. M. McIntosh, and P. T. Doyle. 2004b. Effects of short-term supplementation with selenised yeast on milk production and composition of lactating cows. Aust. J. Dairy Technol. 59:199-203.

Institute of Medicine. 2000. Dietary Reference Intakes for Vitamin C, Vitamin E, Selenium, and Carotenoids. Food and Nutrition Board, Natl. Acad. Press, Washington, DC.

Juniper, D. T., R. H. Phipps, A. K. Jones, and G. Bertin. 2006. Selenium supplementation of lactating cows: Effect on selenium con- centration in blood, milk, urine, and feces. J. Dairy Sci. 89:3544-3551.

Kim, Y. Y., and D. C. Mahan. 2001. Effect of dietary selenium source, level, and pig hair color on various selenium indices. J. Anim. Sci. 79:949-955.

Lawes Agricultural Trust. 2005. Genstat 8. Genstat Statistical Package. 8th ed. Lawes Agric. Trust, Rothamsted, UK.

MacRae, J. 2004. The Underwood Lecture for 2004. Modern Technologies: 75 years of progress, but what are the future needs of our industry. Anim. Prod. Aust. 25:373-384.

McIntosh, G. M., and P. J. Royle. 2002. Supplementation of cows with organic selenium and the identification of selenium-rich protein fractions in milk. Pages 233-238 in Nutritional Biotechnology in the Feed and Food Industries. Proc. Alltech's 18th Ann. Symp. T. P. Lyons and K. A. Jacques, ed. Nottingham University Press, Nottingham, UK.

NRC (National Research Council). 2005. Mineral Tolerance of Animals. 2nd rev. ed. Natl. Acad. Press, Washington, DC.

Ortman, K., and B. Pehrson. 1997. Selenite and selenium yeast as feed supplements for dairy cows. J. Vet. Med. A 44:373-380.

Ortman, K., and B. Pehrson. 1999. Effect of selenate as a feed supplement to dairy cows in comparison to selenite and selenium yeast. J. Anim. Sci. 77:3365-3370.

Standing Committee on Agriculture. 1990. Feeding Standards for Australian Livestock. Ruminants. CSIRO Publ., Melbourne, Australia.

Thompson, J. C., R. N. Thornton, S. N. Bruere, and R. S. Ellison. 1998. Selenium reference ranges in New Zealand cattle. N. Z. Vet. J. 46:65-67.

Thompson, K. G., A. J. Fraser, B. M. Harrop, and J. A. Kirk. 1980. Glutathione peroxidase activity in bovine serum and erythrocytes in relation to selenium concentrations of blood, serum and liver. Res. Vet. Sci. 28:321-324.

Tilley, J. M. A., and R. A. Terry. 1963. A two-stage technique for the in vitro digestion of forage crops. J. Brit. Grassld. Soc. 18:104-111.

Tinggi, U., C. Patterson, and C. Reilly. 2001. Selenium levels in cow's milk from different regions of Australia. Int. J. Food Sci. Nutr. 52:43-51.

Van Soest, P. J., J. B. Robertson, and B. A. Lewis. 1991. Methods for dietary fiber, neutral detergent fiber, and nonstarch polysaccharides in relation to animal nutrition. J. Dairy Sci. 74:35833597.

Walker, G. P., P. T. Doyle, and F. R. Dunshea. 2004. Milk selenium concentration varies with time of year and feeding practices in grazing cows. Asia Pac. J. Clin. Nutr. 13(Suppl.):S84.

White, C. L., A. D. Robson, and H. M. Fisher. 1981. Variation in nitrogen, sulfur, selenium, cobalt, manganese, copper and zinc contents of grain from wheat and two lupin species grown in a range of Mediterranean environments. Aust. J. Agric. Res. 32:47-59.

Witchel, J. J., A. L. Craigie, H. Varela-Alvarez, and N. B. Williamson. 1994. The effect of intraruminal selenium pellets on growth rate, lactation and reproductive efficiency in dairy cattle. N. Z. Vet. J. 42:205-210. 